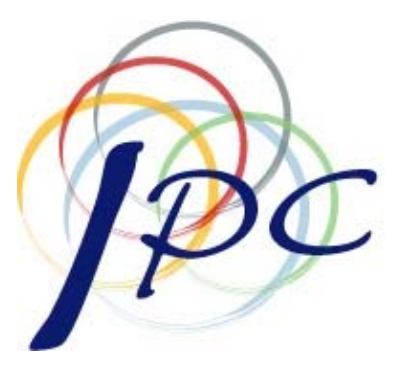

INTERNATIONAL Policy CENTER

Gerald R. Ford School of Public Policy University of Michigan

IPC Working Paper Series Number 109

Fairness in the WTO Trading System

Andrew G. Brown

Robert M. Stern

October 9, 2010 


\title{
Fairness in the WTO Trading System
}

\section{Andrew G. Brown, Amherst, MA and Robert M. Stern, University of Michigan}

\begin{abstract}
We first provide a brief critique of the utilitarian principle as a guide to fairness in the world trading system. We then turn to the alternative conception of fairness in terms of economic equity, exploring the meaning of its two components: equality of opportunity and distributive justice. We thereafter proceed to discuss the conditions of autonomy and reciprocity that have to be met in order to realize greater fairness in multilateral trade negotiations. Next, we comment on aspects of procedural justice that are necessary for the functioning of a fair trading system. Finally, we conclude with an overall assessment of the considerations of the fairness achieved in the Uruguay Round multilateral negotiations.

To be published in Amrita Narlikar, Martin J. Daunton, and Robert M. Stern (eds.), The Oxford Handbook on the World Trade Organization.
\end{abstract}

Keywords: Fairness, Equality of Opportunity, Distributive Justice, Global Trading System

JEL Classification: D63, F02, F10, F13

October 9, 2010

Address correspondence to:

Robert M. Stern

Professor Emeritus of Economics and Public Policy

University of Michigan

4248 Gilbert Street

Oakland, CA 94611

E-Mail: rmstern@umich.edu

Tel. 510-879-7733

http://www.umich.edu/ rmstern 


\section{Chapter}

\section{Fairness in the WTO Trading System}

\section{Andrew G. Brown and Robert M. Stern}

\section{Introduction}

In this chapter, we first comment on the fairness of the multilateral trading system as conducted under the rules and procedures of the World Trade Organization (WTO). ${ }^{1}$ Having been dominated until quite recently by a small number of developed countries, the system has focused heavily on managing the conduct of trade relations among these countries. Ideas of fairness like nondiscrimination and national treatment have played a part in these relations and are woven into the system. However, with the great expansion in membership to include most developing countries, the distinctly different economic conditions of these countries have put the rules and procedures of the system under fresh scrutiny. There is more emphasis on the relevance of fairness in trade relations, but these relations also have to be understood in a broader, more global setting. However, discussion of the issue so far is lacking in coherence. What we attempt in this chapter is to offer a framework within which the fairness of the current system can be assessed.

As a first step, we should state what we understand by fairness. We do so in full recognition that there is no objective, universal definition to which all reasonable persons are likely to agree. We begin from a view of fairness espoused by philosophers since Kant and most recently by Sen (2009) that finds its roots in the impartiality with which we make judgments

\footnotetext{
${ }^{1}$ The WTO came officially into existence on January 1, 1995, following the conclusion of the Uruguay Round (1986-1994) of multilateral trade negotiations. It subsumed the General Agreement on Tariffs and Trade (GATT), which was created after WWII and which provided the framework for seven rounds of multilateral trade negotiations from 1947 to the beginning of the Uruguay Round.
} 
about the distribution of rights and obligations, income and wealth, or other valued attributes. Impartiality demands that we put aside our own preferences or prejudices, and that we take account of the interests and concerns of others. ${ }^{2}$ Arriving at an impartial judgment calls for a reasoned scrutiny of the evidence and arguments. However, as Sen (2009) has observed, the reasoning need not result in only one judgment. There is "a plurality of unbiased principles" that may inform the judgments of reasoning persons. Thus, in the present context of the multilateral trading system, there are two widely known underlying principles that vie with each other for primacy - the utilitarian principle and the principle of economic equity. The former is explicitly or implicitly favored by most mainstream economists, but we hew to the latter as the more persuasive and relevant. As discussed more fully later, we see economic equity as composed of two subsidiary principles: equality of opportunity and distributive justice.

Were the rules and procedures of the multilateral trading system the outcome of an impartial process, they could be declared to be fair (by some impartial standard). As we know, however, they have emerged from numerous rounds of negotiations among countries that not only have diverse interests but also differ greatly in bargaining power. However, because the system is based on voluntary cooperation, considerations of fairness have never been entirely absent from these negotiations (though neither have they been dominant).

It is through the successive rounds of negotiations that a fairer system can gradually be realized. If the initial position was unfair, then the rounds of negotiations, if fair in themselves,

\footnotetext{
${ }^{2}$ Rawls (1971) realizes impartiality in his theory of justice as fairness by postulating an "original position" in which participants decide on a system of justice before they know what their position in society will be.
} 
should lessen the distortions and move the system toward greater fairness. ${ }^{3}$ But what constitutes fair negotiations? Trade agreements reached through multilateral negotiations amount to binding contracts that confer certain rights and obligations on all the participating countries. The process of negotiation is critical for the fairness of the outcome. In principle, the extent to which participants respect each other's autonomy and engage willingly in the reciprocal exchange of benefits goes far toward defining the fairness of the process. As we know, however, and explore later, respect for autonomy and reciprocity is by no means always present.

We begin our discussion with a brief critique of the utilitarian principle as a guide to fairness in the world trading system. We then turn to the alternative of economic equity, exploring the meaning of its two components: equality of opportunity and distributive justice. We thereafter proceed to discuss the conditions of autonomy and reciprocity that have to be met in order to realize greater fairness in multilateral trade negotiations. Next, we comment briefly on aspects of procedural justice that are necessary for the functioning of a fair trading system. Finally, we conclude with a brief assessment of considerations of the fairness achieved in the Uruguay Round of multilateral trade negotiations.

\section{The Utilitarian Principle as a Guide to Fairness}

The mainstream utilitarian principle applied to the trading system derives from the view of rational behavior as the maximization of utility. There is a tacit acceptance that the realization of a more efficient global economy can be a practically acceptable criterion of fairness. Greater efficiency is defined as a movement toward Pareto optimality and, in the context of international trade, that state is reached if no country can be made better off without some other country being

\footnotetext{
${ }^{3}$ It may, however, leave some initial biases untouched because they are not part of the negotiating agenda. This, for instance, is what happened to agricultural tariffs and subsidies from the 1950s until the Uruguay Round in the 1990s.
} 
made worse off. Even in that circumstance, if the losing country can be compensated by the gaining country while still leaving the latter better off, that qualifies as a gain in efficiency. This utilitarian view of fairness posits that, so long as no country suffers a net loss, there are no rational grounds for resisting measures to liberalize trade that benefit the global economy.

But in our view, this criterion has serious limitations as a basis for assessing fairness in the multilateral trading system. That is, the multilateral trading system consists of a set of agreements among trading partners that has evolved over the decades; and these agreements define how the governments of these countries will conduct themselves in their trade relations. It is thus a form of cooperation entered into by independent countries for their mutual advantage and is not necessarily compatible with the utilitarian principle, since all the participants in the system expect some benefit from their participation and none seek per se to maximize global welfare.

But even if we chose to disregard that independent countries cooperate to obtain mutual advantage, the utilitarian principle would be a poor guide to fairness. In practical application, the analysis is based on welfare maximization; it compares the initial situation with the final situation after the policy change has been put into effect and equilibrium has been restored. The difficulty here is that the initial situation is taken as given with respect to the existing distribution of income and wealth and the structure of institutions and policies that will reflect the inequities built into the system. Thus, for many emerging developing countries, a system of trade rules and procedures based on allocative efficiency may well seem unfair to them without consideration of the initial conditions. Strongly held differences of opinion on this issue therefore may limit the possibilities of agreement about the fairness of rules and procedures based on the efficiency criterion. 
The mainstream efficiency criterion has dominated much of the commentary on the multilateral trading system. Unfortunately, this viewpoint abstracts from the world of nation states that constitute the key actors in the WTO system. It does not conceive of the trading system as an evolving body of rules and procedures that nations have entered into to manage their relations in expectation of mutual advantage.

\section{Economic Equity as a Guide}

We favor economic equity as the relevant guiding principle in assessing the fairness of the trading system. It focuses on the distribution among nations of the rights and obligations that constitute the WTO trading system. As already stated, economic equity breaks down into two subsidiary, and related, principles - equality of opportunity and distributive justice. We first explore the meaning of equality of opportunity and thereafter consider how it needs to be qualified to take account of distributive justice.

\section{Equality of Opportunity}

In some of its specific manifestations, such as nondiscrimination, national treatment and fair competition, the principle of equality of opportunity has a long history in trade relations. These norms or rules have evolved over time, being adapted to changing circumstances and being extended to cover a widening range of inter-governmental conduct. Their practical application has undoubtedly enhanced the fairness of the trading system

By ensuring that countries extend the same treatment to all their most favored trading partners, nondiscrimination has been of great importance in the evolution of the multilateral trading system. From the mid- $19^{\text {th }}$ century onward, adherence to nondiscrimination did much to lessen trade rivalries and to provide a foundation for multilateral trade cooperation. However, 
while still an important principle of the GATT/WTO agreements, it has lost some of its practical significance in recent years as regional and bilateral free trade agreements have multiplied. Taken at face value, these agreements run counter to the whole idea of nondiscrimination and so detract from equality of opportunity. Through the trade diversion that they cause, these regional or bilateral agreements may penalize third countries in ways that, for them, are quite arbitrary. However, in recognition that political and trade relations among countries are not set in stone, the formation of customs unions (CUs) and free trade areas (FTAs) has long been accepted under the GATT/WTO agreements. Member countries are free to enter into these preferential arrangements without legally breaching the principle of non-discrimination. An intellectual defense of this formal inconsistency would be that this is a situation in which the principle of the greater good should override that of equality of opportunity. So long as the trade created by the $\mathrm{CU}$ or FTA is greater than the trade that is diverted, the world is better off. ${ }^{4}$ Still, harm is nonetheless done to individual third countries. ${ }^{5}$ Worse, being negotiated outside the framework of the WTO disciplines and procedures, some FTAs reveal a deliberate disregard for the idea of fairness as understood in multilateral trading relations. When drawn up between a powerful country and a small and weak country (or countries), the former has not always resisted the temptation to impose conditions on the latter that would not be acceptable in less asymmetric multilateral negotiations. ${ }^{6}$ The larger political reality, however, is that, since virtually every

\footnotetext{
${ }^{4}$ While raising few objections to such regional agreements as the European Common Market or the North American Free Trade Agreement, most trade economists emphasize that the proliferation of FTAs is likely to have adverse effects because the tangle of differential tariffs and rules of origin would distort trade flows and diminish global efficiency.

${ }^{5}$ It is a fact, however, that affected third countries have quite often been able to take countermeasures notably, negotiating their own FTAs - to lessen the damage.

${ }^{6}$ For example, the conditions that the United States included in its FTAs with Chile and Singapore were intended to prevent these countries from resorting to controls over capital outflows even in the event of a
} 
nation state has entered into at least one FTA, very few voices have been raised denouncing such agreements as breaches of nondiscrimination.

National treatment, which is also embedded in the GATT/WTO rules, is another limited expression of the principle of equality of opportunity. National treatment has been closely associated with the negotiation of reductions in border barriers since countries have wanted assurances that concessions won in reducing these barriers would not be defeated by the use of discriminatory domestic measures. In recent decades, as border barriers have diminished and increasing attention given to the role of domestic regulations in impeding trade, scrutiny of national practices that might be deemed to be discriminatory has intensified. Indeed, a substantial number of the complaints brought to the WTO Dispute Settlement Body since its establishment in 1995 have turned around the question of national treatment.

Fair competition, though lacking the formal standing of nondiscrimination or national treatment, is another norm that has further extended the idea of equality of opportunity. Countries have wanted to be assured that their firms would be able to compete fairly with foreign enterprises, whether in foreign or domestic markets, and rules have been introduced to discipline the use by governments of particular measures that distort competition. A long-standing complaint, for instance, had been the use of subsidies that give foreign firms a competitive edge, and subsidy agreements now limit or prohibit the use of specific forms of subsidies.

At least since the initiation of the Uruguay Round in 1986, a decidedly more expansive view of equality of opportunity has come to permeate the discussion of multilateral trade relations. Equality of opportunity, at its extreme limit, would imply that the firms of different countries are able to have access to, and to do business in, each others' markets under the same stricter intellectual property rights than prevail under the WTO agreement. 
regulatory conditions as they have in their own domestic market. There would, in effect, be a single, integrated market. Such a "level playing field" virtually exists for some products in the markets of some participants in the trading system, but it is very far from being the rule. To insist on such an extreme interpretation of the principle of equality of opportunity would be to make a wholly integrated world market the ultimate standard of fairness in multilateral trade. In a world of nation states which differ vastly in power, in levels of development, in institutions, and in their histories of trade relations, that seems too great an abstraction to be useful. Although the trend has been both toward the reduction of barriers at the border and toward some limited convergence in domestic regulations, wide differences in the content of countries' border and domestic regulations remain.

These differences sometimes have origins of an administrative or technical nature such as in customs procedures or technical standards. In these cases, there can be sizable practical difficulties in formulating common rules, not least in the overcoming of entrenched interests in long established practices. Arriving at a solution is for the most part a matter of finding an equitable sharing of the burden of adjustment that countries have to make in order to introduce more comparable practices.

Differences in national regulations or practices, however, may also arise from strongly held social preferences that reflect countries' social mores, their institutions, or particular level of economic development. These national preferences place valid limits on the scope of the multilateral rules that can be negotiated to realize greater equality of opportunity. For instance, in the name of fairness, many in the United States and European Union have advocated the inclusion of labor standards in the WTO agreements as a way of countering competition from "sweatshop labor". Others, especially from emerging countries, have argued strongly against 
such an action. One fear is that such standards would be abused for protectionist purposes. A more intrinsic objection is that it is very difficult to arrive at definitions of labor standards that are both sufficiently specific for dispute settlement purposes and would be widely acceptable. The particular labor standards acceptable in individual countries are shaped uniquely by their own social and political histories. As the experience of including labor standards in FTAs has demonstrated, the accommodation of distinctively different social norms and practice in common rules has defeated negotiators, and at best, they have agreed that each trading partner will actively undertake to enforce its own labor standards. ${ }^{7}$ Again, there are numerous complaints directed against the trading system about unfair pricing and many of these instances imply some form of restrictive business practice. ${ }^{8}$ However, because of national differences in views about acceptable forms of business organization, a consensus on competition policy has so far been beyond the reach of WTO members and there is no corresponding set of rules that can be applied.

Clearly, there are many national regulations and procedures that presently lie outside the scope of WTO disciplines. The firms and individuals of each country may sometimes choose to regard the different regulations and procedures of the other countries as unfair but, from the viewpoint of the impartial spectator, they can only be described as different. It has to be accepted that when the differences reflect strongly held national preferences, these limit the scope for multilateral rules that would enhance equality of opportunity (at least so long as the autonomy of the individual countries participating in rules formation is respected).

\footnotetext{
${ }^{7}$ For a fuller discussion, see Brown and Stern (2008).

8 Anti-globalization critics find some business practices unfair - for example, the displacement of smallholders by agro-businesses - that are nonetheless accepted or condoned by governments of the trading countries. These are more in the nature of criticisms of the social system and lie outside our discussion.
} 


\section{Distributive Justice}

In the view that we espouse, the principle of equality of opportunity has to be qualified to take account of distributive justice. For most of us, the great disparity in levels of living among countries imposes a moral obligation on the richer countries to assist the poorer countries in the alleviation of dire poverty. While the provision of financial aid is the most obvious expression of this obligation, foreign trade is also widely accepted as a major means of economic betterment; and there are therefore grounds for extending favorable trading conditions to these countries.

But what do favorable conditions mean in the context of the multilateral trading system? Distributive justice patently does not mean the utilization of the system to transfer resources from rich to poor nations. The trading system is not a vehicle for the transfer of resources but an arrangement for promoting commercial relations among firms and individuals in different countries to their mutual benefit. What it can only mean in this context is that the system should specially favor the economic growth of the poorer countries; and this can happen in but two ways. First, it can improve the access of these countries to foreign markets. This potentially contributes to their economic growth by enlarging the market for domestic producers and enhancing specialization; and it can have such beneficial longer-term consequences as the promotion of learning, the realization of economies of scale, and the introduction of technological improvements. Second, and - for some - more controversially, the system can allow the poorer countries to practice greater protection of their domestic markets. This, especially in the earlier stages of development, potentially encourages new domestic firms (whether nationally or foreign owned) to establish themselves, to expand production, and to make innovations, so that they can form the core of an expanding modern sector. How far the GATT/WTO system, which has historically focused primarily on the reciprocal improvement of 
market access among trading partners, should be adapted to accommodate these two developmental objectives has been, and remains, a matter of controversy (it has been a theme running through the faltering Doha Development Round), and the positions taken on this issue deeply affect views about the fairness of the system.

Preferred access for developing countries to the markets of the richer countries has long been a formal feature of the trading system. Several non-reciprocal preferential programs are features of the system. The richer countries launched the Generalized System of Preferences (GSP) in the 1970s. In addition, the United States, the European Union, and other developed countries operate other, still more favorable schemes for particular groups of countries, such as the countries of Sub-Saharan Africa under the U.S. African Growth and Opportunity Act (AGOA) or the EU Cotonou Agreement that favors the African, Caribbean, and Pacific former colonies. Further, the developed countries generally provide still more extensive preferences to the least developed countries.

There are grounds for skepticism about the practical value of these preferential arrangements for developing countries as a whole. The evidence is that the possibilities of preferential access are far from having been fully utilized, probably because exporters have had difficulty in complying with rules of origin or because the transactions cost of the certification process have outweighed the saved preferential margin. More fundamentally, a number of emerging countries - China being the outstanding instance in recent years - have achieved a remarkable export performance without the benefit of any preferential treatment. This only emphasizes that, in the relatively open trading system that now prevails, the dominant determinants of export performance lie in the internal economic growth, structural change and export-oriented policies of the exporting countries themselves. Such doubts about the practical 
value of broad-based preferences ${ }^{9}$ may even apply, in some degree, to the more generous preferential arrangements for the least developed countries at their earlier stage of development. $^{10}$

In aiming to ease market access on grounds of distributive justice, the rich countries are open to the major criticism that they have confined their efforts to preferential arrangements for tariffs on a range of industrial products (with these countries excluding some of the more "sensitive" - and usually labor-intensive - products.) This has entirely failed to address some of the more deeply embedded discriminatory trade barriers that developing countries face in exporting to the rich countries. The most stubborn is the tariffs and subsidies with which the rich countries protect their agricultural markets. The Agricultural Agreement of the Uruguay Round and the uncompleted negotiations of the Doha Development Round have left this bias against developing country agricultural exports largely unchanged. Other embedded features of rich countries' trade barriers are relatively high tariffs on labor-intensive products and the escalation of tariffs by degree of processing on primary products. ${ }^{11}$

On the other side of the coin - the protection of their own markets - developing countries have sought in multilateral trade negotiations to preserve their margin of protection by insisting that they grant less-than-full reciprocity to the rest of the world. In addition, they have sought to retain flexibility by binding their tariffs at relatively high levels even though many have made

\footnotetext{
${ }^{9}$ For a review of the literature on the benefits of preferences for developing countries, see Hoekman and Ozden (2006). For a more detailed discussion of these doubts, see Brown and Stern (2007).

${ }^{10}$ At a forum marking the $10^{\text {th }}$ anniversary of the passage of the African Growth and Opportunity Act, the U.S. Secretary of State, Hilary Clinton, told delegates: "We all know, despite the best of intentions, Agoa has achieved only modest results and has not lived up to the highest hopes of a decade ago...." Financial Times, 8/9/10.

${ }^{11}$ Removal of these biases would, it might be noted, be better described as steps toward greater equality of opportunity rather than as measures taken in the name of distributive justice to provide particularly favorable market access.
} 
substantial cuts in their applied tariffs. Developing countries, however, face a quandary since bargaining to gain improved access to the markets of rich countries means offering concessions in their own tariffs.

It is, however, not only more favorable tariff regimes that concern developing countries. Equally important - or perhaps more so - is that these countries should enjoy greater flexibility in the use of domestic measures that may promote their development but that are subject to WTO disciplines. This is discussed more fully in the next section.

\section{Fairness in the Negotiation of Trade Agreements}

In the real world, what matters is how far the principle of economic equity is translated into practice through multilateral negotiations, and that depends on the fairness of the negotiating process. The participating countries have to enjoy both autonomy in their decision making and reciprocity in the negotiation of benefits.

\section{Autonomy}

Multilateral negotiations are conducted on the premise that all member countries will concur in the final package of negotiated agreements as a "single undertaking". The agreements are thus based on the consent of the participants, so that the obligations which they accept are self-imposed. The voluntary nature of the agreements, however, is by no means sufficient to ensure that they are fair. Participants differ greatly in their bargaining power as well as in their bargaining skills. The weaker participants may consent to a negotiated agreement simply because of their lack of acceptable alternatives. It is quite possible, for example, for a weaker participant to accept the outcome of a round of negotiations that leaves it worse off than before. A government could therefore consider in such a circumstance the alternative of withdrawing from 
membership of the WTO. But this would mean the loss of more fundamental rights like mostfavored-nation and national treatment, which would be difficult to give up.

While there has been a significant shift since the Uruguay Round in the negotiating power of participating countries, the balance of advantage still lies markedly with the most developed countries of North America, Europe, and Japan. Supported by their technological leadership and political power, they have hoped that the regime of open-market access which leaving aside agriculture - they have developed among themselves, could be enlarged to embrace the developing countries as well. The developing countries, however, have the more complex aim of wanting to improve their market access to other countries while defending the firms in their emerging modern sectors from being eclipsed by highly competitive, and more experienced, foreign enterprises.

Many suggestions have been made for improvements in the negotiating process so that the smaller and weaker countries have a larger voice in the deliberations. Some of the larger emerging countries - Brazil, China, India, and South Africa - acquired a new eminence in the suspended Doha Development Round. However, "mini-ministerial" meetings deciding common positions have still excluded the smaller and weaker countries from participation. Even relatively large countries have complained strongly about some negotiating procedures. For example, in the Uruguay Round, the major content of the Agreement on Agriculture was drafted by the United States and the European Communities - known as the Blair House agreement - and presented to the other participants, some of whom were major traders in agricultural products, as a sine qua non of the final agreement (Cedro and Vieira, 2010). A more open and inclusive process would undoubtedly contribute toward improving the perception that the negotiating process was not unduly weighted in favor of the most powerful countries; and, it should be noted that the 
Director General of the WTO has made efforts in the course of the Doha Development Round to effect some improvements - such as inviting more countries to participate in the formerly exclusionary "Green Room" negotiations.

The real test, however, of the fairness of the negotiating process lies in whether the outcome is seen to be mutually beneficial for all participants. In other words, if the agreements arising out of a round of negotiations are to approach our idea of fairness, it is not enough that the member countries should participate in the negotiations and willingly consent to the decisions; it is also necessary that the agreements should yield benefit to all. How far such reciprocity is met is by no means always easy to determine in actual practice. We explore what reciprocity has practically meant in the following section.

\section{What Reciprocity Means Practically}

\section{Regarding Market Access}

In the context of international trade relations, reciprocity has usually been taken to mean that the participants in any negotiations enjoy roughly equivalent benefits or bear roughly equivalent costs. These benefits and costs, it should be remembered, do not correspond to the economist's concept of economic welfare. Mainstream economists are interested in the consequences of trade liberalization - both the gain in access to foreign markets and the reduction in trade barriers on imports - in enhancing the efficient use of productive resources in the economy. But trade negotiators tend to take a more limited view of benefits and costs; these refer primarily to the prospective increases in trade flows that follow from the greater market access granted by other trading partners or conceded to other partners.

In the early post-WW2 days of multilateral trade negotiations, it was relatively clear what the realization of equivalence in market access meant. Countries, which were almost all 
developed countries, negotiated reductions of industrial tariffs or quantitative restrictions on a product-by-product basis that involved comparable amounts of trade. Introduction of across-theboard cuts of tariffs did not seriously impair this perception of equivalence. An equal percentage cut in tariffs across-the-board was taken to imply equivalent gains in market access, an assumption made more plausible by the fact that trade among the developed countries was largely intra-industry trade. The effects of the tariff-cutting formulae, however, became more complicated as they endeavored to take account of differences among countries in tariff peaks and to differentiate among developed and developing countries and as countries sought to exempt lists of specific products from the cuts. It can very reasonably be maintained that the greater complexity in the formulae evolved as a consequence of efforts to improve the fairness of trade-liberalization agreements. However, the effect of the adopted methodology combined with the increasing number of countries participating in the negotiations has been that, for many individual countries, any close correspondence between the gains in market access granted and received has ceased to be apparent. Finger, Reincke, and Castro (2002) demonstrated this clearly for the Uruguay Round. They found that the tariff cuts and affected trade flows that were granted and received by many individual countries failed to balance out.

There is a further complication in the assessment of reciprocity. It is quite often an oversimplification to say that the benefits and costs of gains in market access can be equated with the expected changes in trade volumes. Trade negotiators often have also to take into account the political costs of the domestic adjustments that are generated by the lowering of import barriers. The question then becomes whether the proposed gains in market access more than balance the political and social costs of the adjustments that have to be made. For instance, in the negotiations conducted on agricultural market access during the suspended Doha 
Development Round, the United States negotiators were concerned that U.S farmers would not accept the proposed reductions in agricultural subsidies unless they were compensated by sufficiently large gains in access to foreign markets. Again, the EU was reluctant to reduce its agricultural tariffs significantly if its firms in the manufacturing and service industries failed to enjoy sufficient gains in market access and act as a counterweight to the agricultural interests. For their part, India and China (as well as more developed countries like Japan and South Korea) were concerned with the social and political effects of lowering their agricultural tariff barriers on their huge peasant populations. The question for negotiators from each country was whether the balance of conflicting domestic interests was acceptable.

Still, despite these complications, it does appear that in the bargaining to improve market access through tariff reductions, inter-country reciprocity is not entirely forgotten. Though equivalence may not be a primary concern in the final stages of negotiations, countries nonetheless want to be assured that all participants have made "an appropriate contribution" to the enhancement of market access (Finger, Reincke, and Castro, 2002).

When it comes to the service industries, equivalent gains in market access have again been a relevant concern in negotiations among the rich countries. Having highly developed service industries, most of these countries have been able to see opportunities for expansion in each others' markets if market access is improved. Between developed and developing countries, however, the possibilities for negotiating equivalent gains in market access are much more limited, since the latter's service industries are generally less developed (though there are some notable exceptions such as some IT services or construction services). As a consequence, the market opening of service industries in developing countries has tended to be a more one-sided gain for the rich countries. 
The conclusion we can draw is that, when trade negotiations to improve market access were very largely among the developed countries, the idea of reciprocity - understood to imply equivalence - may have worked well enough. But when the participating countries are as numerous and varied as they are today, it becomes a much less transparent and effective guide to fairness. The dissimilarities among countries in productive structures are too great to allow for intra-sectoral reciprocity. There is further the fact that, as discussed in the next section, the supporting rules of the WTO system also have both effects on market access and create costs for countries. Thus, the assessment of reciprocity has to be made not only on the basis of border barriers but also in regard to changes in the system as a whole. We will return to this point after commenting on the process of rule formation.

\section{Regarding Rule Formation}

Besides drawing up agreements on reductions in tariffs and other principal barriers to market access, the rounds of GATT/WTO negotiations have produced a growing number of other rules that improve equality of opportunity. These rules may seek to remove impediments to trade that arise from complex or opaque domestic regulations; or they try to prevent the discriminatory use of these regulations; or they prohibit or limit the use of measures by governments that are considered to constitute unfair interventions in freely competitive privateenterprise markets. Some major examples are customs procedures and valuation methods, health and safety standards, and subsidies.

While governments have collectively consented to these rules, the adoption of specific rules has not necessarily been to the benefit of all. Since it is the agendas of the most powerful countries that primarily drive rule formation, there is evidently no assurance of reciprocity in the negotiation of particular rules. This said, we should nonetheless first note that some rules do give 
rise to net benefits that are generally shared. This is most probably the case where the impediments to trade have arisen largely from technical differences among countries. Customs procedures and standards are instances. The agreements reached during the Tokyo Round on standards, for example, brought greater uniformity into the technical regulations that were applied nationally to individual products. While recognizing the right of countries to devise their own regulations in matters like health, the environment, and consumer safety, the agreements encouraged countries to move toward internationally agreed standards that would facilitate the flow of trade. Greater transparency in national inspection and certification procedures has also been required, lessening the fear that technical standards might be used in a discriminatory way. Countries have recognized a common benefit in conforming their regulations.

A significant qualification, however, to the fairness of introducing such new rules arises from the fact that numerous developing countries face considerable practical problems in implementing them. It has, for instance, often proved burdensome for countries to have to comply with technical standards set by developed countries that require complex certification and testing procedures. Moreover, there are numerous countries that do not have long histories as independent states and are without well established central administrations or whose small size gives rise to administrative diseconomies; and they have difficulty meeting their formal obligations without undue strain on their resources. It is true that some leeway has generally been granted the poorest countries under clauses according "special and differential treatment," but these have often been unrealistically time limited.

The fairness of rules is less clear cut when these attempt to reconcile different national practices that are rooted in strongly held national preferences. It has long been recognized, for instance, that subsidies could nullify or impair market-access commitments made by countries in 
trade negotiations, and that some multilateral discipline was accordingly needed. But, while virtually all countries make use of subsidies for diverse economic or social purposes, their practices vary widely. The differences in the economic use of subsidies turn essentially on the perceived role of the state in the economy. The United States has emphasized reliance on marketbased decisions (at least in buoyant times) and, in the Uruguay Round, it sought a broad definition of what constitutes a subsidy and a narrow definition of subsidies that were not "actionable" under GATT/WTO rules. Most other countries, both developed and emerging, sought a more restricted definition of a subsidy and more inclusive definition of non-actionable subsidies. Compromises were made for the sake of reaching some agreement, but that clearly left room for a range of views - based on different economic beliefs - about the fairness of the adopted rule.

Some new rules introduced by developed countries, however, have patently not been based on any recognition of mutual advantage. They have been advanced on the basis of superior bargaining power and are particularly hard to defend as fair. A major criticism voiced by the emerging countries of the rules formed during the Uruguay Round is that some placed undue constraints on their development-policy options. The new subsidy rule just mentioned was one source of concern. So too was the agreement on investment (TRIMS) that put restrictions on national development policies, most especially in prohibiting the use of restrictions on import content of foreign direct investment in order to promote backward linkages. In this context, acknowledgment by the developed countries of the principle of distributive justice has largely been confined to the "special and differential treatment" accorded to the least developed countries. 
The agreement on intellectual property rights (IPRs) stands on its own as a particularly egregious instance of a new condition being introduced into the WTO system of rules and procedures without an adequate basis of common consent. For a number of countries, the Agreement on TRIPS lacked any evidence of net benefit and, indeed, was clearly negative for some. Moreover, until later modified, it rode roughshod over the public-goods preferences of many countries for the health of their populations.

\section{A More Inclusive Assessment}

Given the comprehensive nature of trade negotiations covering both market access agreements and rules agreements, we need to ask whether fairness is respected when we take all the agreements together as a single package. Do the negotiations promote greater equality of opportunity and do they enhance distributive justice? There is unfortunately no common measure of the gains in opportunity to trade of individual countries or groups of countries and only subjective, qualitative assessments can be made. Moreover, a comprehensive assessment has to allow for the possibility of large differences in adjustment costs and for possible restrictions in the freedom to pursue developmental measures that restrict market access.

Take the Uruguay Round as an example. If we look at its outcome, it would be reasonable to conclude that at least the rich countries moved toward greater equality of opportunity through the roughly comparable reciprocal measures that they adopted in each of the major areas of negotiation. In industrial tariffs, for example, though the average reduction was not identical, the differences were small and tariff levels were, in any case, low. In a number of service industries, negotiators gained comparable treatment in each others' markets, an improvement that their comparably developed service industries were able to take advantage of. In agricultural trade, both the U.S and the European Communities very largely succeeded in 
preserving most of the measures that protected their own industries. In the formation of new rules, it is true that they did not always share the same views - as, for example, on subsidies but they mostly had similar concerns and neither side dominated the final agreements.

In assessing the outcome of the negotiations between the rich countries and the emerging or developing countries, the question is more complicated. We have to ask not simply whether the negotiations brought reciprocal gains for both groups of countries (in terms of improved market access), but also whether the gains favored the emerging or developing countries; and we have further to ask whether there were large adjustment costs or loss of freedom to utilize developmental measures. The task is made yet more difficult by the fact that there is not the same intra-sectoral comparability in the concessions given and received as there is among developed countries alone.

In the trade of manufactures, the most dramatic gain for the developing countries was purportedly the gradual dismantling of the Multi-Fiber Agreement (MFA). They also benefitted from the general tariff reduction of the rich countries. In return, many developing countries bound their tariffs and removed quotas or made limited reductions in their bound tariffs. (However, the wide gap between bound and applied tariffs, robbed some tariff concessions of much practical significance. On the other hand, numerous countries were unilaterally reducing their tariffs.) In agriculture, the developed countries made little in the way of concessions, thus failing to improve market access for the appreciable number of developing countries with a strong comparative advantage in agricultural products. While developed countries appreciably liberalized access to some service sectors - notably, the financial and telecommunications industries - there were substantially fewer concessions made by developing countries since their 
service sectors were less developed. Still, the concessions made on both sides very largely benefitted the service industries of the developed countries.

Among the new rules adopted in the Uruguay Round, some had market-opening effects in developing countries. But there were also other, and probably more important, consequences of the new rules that were introduced. First, some deprived developing countries of flexibility in the measures they could use to promote their development. Second, the introduction into the system of trade rules of a new regime on intellectual property rights placed new restrictions and costs on the developing countries in the use of new technologies. Third, for many smaller countries, the new rules added to the administrative costs of participating in the system.

What can we conclude then about the fairness of the Round? In terms of the other principle of equality of opportunity, when considered alone, both developed and developing countries won some improvements in access to each other's markets, and the gains may possibly not have been too dissimilar. The difficulty comes when we introduce the principle of distributive justice. The improvements in market access made by developed countries did little to remove major trade barriers like agricultural protection or other biases like tariff peaks on laborintensive products. In supporting rules, while the developmental status of the poorer countries was formally recognized through such measures as special and differential treatment, the broad thrust of the agreements adopted in the Round was to restrict the space that developing countries had to use developmental measures.

\section{Procedural Justice}

We have already commented on procedural justice in the negotiation of trade agreements. But if fairness is to be respected, it is not less important in the implementation of these 
agreements. A fair dispute settlement procedure is necessary to resolve the differences in interpretation of rules that inevitably arise.

Most commentators would agree that the dispute settlement procedure established in the WTO has worked well. No one has seriously questioned the impartiality of the Dispute Settlement Body. Moreover, it has been careful in its judgments not to venture beyond the limits set by the rules that were established consensually by the member countries. Of course, trade lawyers and diplomats have often disagreed with the particular judgments made in specific cases. Each adjudicator brings his or her own normative or causal beliefs to the interpretation of the rules and the review of the evidence, but - as we observed in the introduction - so long as the process is conducted impartially, its fairness is not in question.

One major complaint that can be made against the dispute settlement procedure is that it demands specialized legal and informational expertise to present and argue a case. Many smaller and poorer countries are thus put at a serious disadvantage since they have numerous other competing claims on their limited resources. ${ }^{12}$ It has also sometimes been argued that smaller countries are at another disadvantage in disputes with large countries because their power to enforce any ruling by the Dispute Settlement Body is slight. If a small country is authorized to raise its import duties against a large country because the latter fails to conform to a ruling, the effect of its action will be much less than if the positions are reversed. However, the experience so far has been that - for reputational reasons - the powerful have been willing to respect the rulings of the Dispute Settlement Body. ${ }^{13}$

\footnotetext{
${ }^{12}$ For a discussion of this point, see Hoekman and Mavroidis (2000).

${ }^{13}$ For a more detailed discussion of fairness in the dispute settlement process, see Brown and Stern (2009).
} 


\section{Conclusion}

The completion of the Uruguay Round and the founding of the WTO were a milestone in the long struggle to establish a rules-based system governing multilateral trade relations. The evolution of this system has made possible, though it has not assured, the advancement toward greater economic equity in trade relations.

Ideas of fairness have been translated into practice through successive rounds of negotiations. For the large developed countries - primarily the United States and the European Union - a key issue in the negotiation of greater market access and improved rules has been whether benefits have been perceived to be reciprocal. Through these negotiations, they have moved gradually toward the realization of greater equality of opportunity in their trade relations. However, for the growing membership of emerging or developing countries - many of whom were non-members or only passive members until the Uruguay Round - we have argued that, in the name of fairness, equality of opportunity should also be qualified by the principle of distributive justice.

Taking greater equality of opportunity on its own, its realization in negotiations between developed and developing countries has been difficult to assess. The differences between these countries, and among the developing countries themselves, in levels of living and economic structures have not allowed any close matching of reciprocal benefits. Still, though there have not necessarily been reciprocal gains in market access or in the improvement of rules, the imbalances may not have been too great for most countries. The rounds of negotiations conducted so far, however, have left some long embedded impediments to trade on both sides largely untouched. 
In qualifying the principle of equality of opportunity to meet the demands of distributive justice, the weight given by an impartial spectator to the latter depends on his or her causal, as well as, normative beliefs. There are valid differences of view about the place of protectionist trade measures in national economic development. The same spectator may, moreover, very reasonably modify his or her causal beliefs in the light of the size and resource endowment of the specific country or countries being considered. In other words, if fairness is defined by equality of opportunity qualified by a sense of distributive justice, we have to accept that there is always scope for differences in impartial judgments about the fairness of any trading system. The best we can do is to ensure that the system accommodates these differences of view by not allowing one viewpoint to dominate the rules and procedures.

\section{References}

Brown, Andrew G., and Robert M. Stern. 2009. "Issues of Fairness in WTO Dispute Settlement," in James C. Hartigan (ed.), Trade Disputes and the Dispute Settlement Understanding of the WTO: An Interdisciplinary Assessment. Frontiers of Economics and Globalization, Volume 6, Emerald Publishing Ltd.

Brown, Andrew, and Robert M. Stern. 2008. "What are the issues in using trade agreements to improve international labor standards?" World Trade Review.7:2, 331-357.

Brown, Andrew, and Robert M. Stern. 2007. "Concepts of Fairness in the Global Trading System," Pacific Economic Review.12:3 293-318.

Cedro, Rafael Rosa, and Bruno Furtado Vieira. 2010. “John Rawls' Justice as Fairness and the WTO: A Critical Analysis on the Initial Position of the Multilateral Agricultural Negotiation," The Law and Development Review 3:2, 5. 
Finger, Michael J., Ulrich Reincke, and Adriana Castro. 2002. "Market Access Bargaining in the Uruguay Round: Rigid or Relaxed Reciprocity” in Jagdish Bhagwati (ed.), On Going Alone: The Case for Relaxed Reciprocity in Freeing Trade. Cambridge Ma.: MIT Press.

Hoekman, Bernard and Petros Mavroidis. 2000. "WTO Dispute Settlement, Transparency and Surveillance," The World Economy. 23:4 527-542.

Hoekman, Bernard and Caglar Ozden (eds.). 2006. Trade Preferences and Differential Treatment of Developing Countries. Cheltenham: Edward Elgar Publishing.

Rawls, John. 1971. The Theory of Justice. Cambridge Ma.: Harvard University Press.

Sen, Amartya. 2009. The Idea of Justice. Cambridge Ma.: Harvard University Press. 